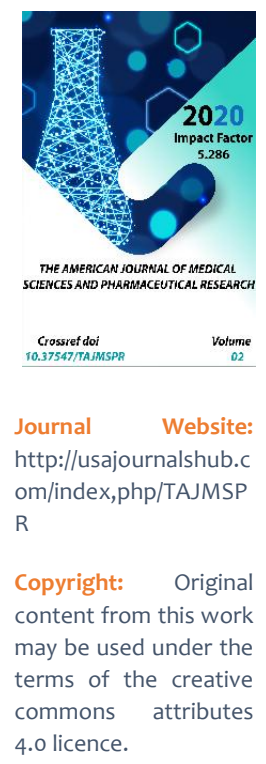

\title{
Language And Teeth Information Carriers State Of Internal Organs
}

\author{
Sevara Atakhanovna Fayziyeva \\ Doctor Dentist, Teacher At The Department Of Therapeutic And Orthopedic Stomatology \\ International Kazakh-Turkish University Named After Hodja Ahmed Yasaui. Kazakhstan \\ Sirojiddin Makhammadaminovich Irismetov \\ Doctor Dentist, Teacher At The Department Of Surgical And Pediatric Stomatology \\ International Kazakh-Turkish University Named After Hodja Ahmed Yasaui. Kazakhstan
}

\section{ABSTRACT}

As a result of electron-microscopic examinations, enamel prisms in the transverse position, they look like arches and roofs. When we cross the enamel prisms, we see diagonals, polygonal prisms. When they are parallel, when they are cut lengthwise, we see the planes, the fibers parallel to each other. Because enamel prisms are curved in an S-shape, some appear transverse and others parallel when cut. The result is light and dim roads, called Schroeder roads.

\section{KEYWORDS}

Oral cavity, gums, function, lips, tongue, cheeks and palate, medial and distal surfaces.

\section{INTRODUCTION}

The front of the mouth is the upper and lower lips, and the top is hard and soft. There is a tongue at the back and a tongue at the bottom. There is a mouth and neck muscles (mouth diaphragm) under the tongue. With the help of teeth, the oral cavity can be divided into two parts. There is an anterior entrance, a corridor, and a main oral cavity.
The mouth is covered with a mucous membrane. Teeth begin to form at 2 months, 6 to 7 weeks of gestation. The development of teeth is divided into 3 stages: a) the formation of tooth buds; b) period of tooth development; d) formation of tooth tissue. First deciduous teeth are formed, then permanent tooth buds and develops. Thus, 
the alveoli are basically made up of three parts: a) the enamel organ, b) the tooth sucker, and d) the alveolar sac.

\section{THE MAIN RESULTS AND FINDINGS}

The hardest tissue of the teeth, the enamel, develops from the enamel, and the odontoblast cells of the tooth pulp form the tooth's dentin. From the alveolar sac, alveolar growths of cementum, periodontium, periodontium, and jawbone are formed at the root of the tooth. The accumulation of mineral salts begins at the junction of enamel and dentin. The enamel is the outer and inner layers of the body, between which cells are formed, which form the outer layer of the tooth enamel, mainly the membrane that covers the surface of the tooth enamel Nasmitt's membrane. It consists of interprismal intermediates. The dentition and sac are rich in lymph, blood vessels, and nerves.

They are tooth buds ensure normal development and growth. When the prisms in the enamel are 20 microns, the accumulation of salts begins. Enamel development lasts up to three months. The amount of water and organic matter in the enamel tissue decreases, mineral salts increase and crystals form. The formation of enamel leads to the formation of tooth crowns. Enamel growth begins at the enamel border and extends to the surface of the tooth crown. The enamel layer is located on the crown of the tooth and forms a percussion, ie in the form of a round wavy roller. Cementoblasts are formed from epithelial cells on the surface of the alveoli. They form the cement at the root of the tooth. As the corona grows in the mouth, the root of the tooth begins to develop. This process takes two to three years. As the root of the tooth grows, the epithelium stops growing into the connective tissue.
Enamel is the hardest tissue in the human body. Enamel consists of $95 \%$ inorganic mineral salts and consists mainly of hydroxyapatite crystals: average calcium - 37\%, phosphorus - $17 \%$. It contains $1.2 \%$ organic matter and $3.8 \%$ water. Due to the small amount of organic matter, the metabolism of enamel is very slow. Regeneration is almost imperceptible in the enamel. Some scientists are wrong to say that enamel is not alive, because at least a little metabolism is in enamel. So enamel is also a living tissue. The main organic matter in enamel is proteins, including lepids, amino acids, citrates, and polysaccharides. Thus, the composition of the enamel is very complex. Enamel metabolism is mainly due to saliva in the mouth. Enamel covers the crown of the tooth, mainly in the cavities forms a thick layer of enamel, 2-3 mm, the enamel becomes thinner towards the root of the tooth, and the enamel becomes thinner around the neck. Enamel is hard, shiny, brittle. The histological structure of the enamel consists mainly of enamel prisms and interprism substances. In the newly formed tooth, the crown of the tooth is covered with a thin membrane - the nasal layer - the cuticle. The cuticle is eaten after some time as a result of the chewing process and remains only in the neck of the tooth, which is attached to the gum epithelium, which is the base of the physiological tooth-gum pocket and is $2 \mathrm{~mm}$ deep.

As a result of electron-microscopic examinations, enamel prisms in the transverse position, they look like arches and roofs. When we cross the enamel prisms, we see diagonals, polygonal prisms. When they are parallel, when they are cut lengthwise, we see the planes, the fibers parallel to each other. Because enamel prisms are curved in an Sshape, some appear transverse and others parallel when cut. The result is light and dim 
roads, called Schroeder roads. The development of enamel has led to the discovery of different, different amounts of mineral salts, called Retsius pathways.

Dentin. Dentin contains $70-72 \%$ of inorganic matter, the main part of which is calcium salts of phosphate and carbonate, a small amount of calcium fluoride, magnesium, sodium and other trace elements. $28-30 \%$ consists of water and organic matter, ie protein, fat and carbonated water. Dentin is similar in structure to bone, and in its histological structure it consists mainly of dentinal pathways, channels and the main substance. The average diameter of each dentinal canal is 1-5 microns.

The main material of dentin consists of radial and tangential, collagen and pericolagenic fibers. Radial fibers - Corfa fibers and tangential fibers - are called Ebner fibers. There are more radial fibers on the outside of the dentin near the enamel, and tangential fibers on the inner surface near the pulp.

Among the fibers is an amorphous adhesive. The outer part of the dentin close to the enamel is called the placental dentin. Near the inner pulp is predentine, which is much less mineral salts. Predentin is the basis for the formation of dentin. The dentinal canals are round, oval, and oval in cross-section, starting at the pulp chamber of the tooth. They twist and wave radially through the main substance of the dentin and expand mainly in the form of cones, ending at the enamel dentin boundary. Inside the dentinal canal is a long network of odontoblasts - the Thoms fiber. This fiber mainly nourishes the dentin, partly the enamel and provides the nerve.

The organic basis of dentin is tri calcium phosphate and hydroxyapatite salts and crystals. The part of the dentin, rich in mineral salts, is called the hyper mineralization zone. The root of the tooth is low in mineral salts.

The pulp is the inner cavity of the tooth - the pulp chamber, where the tooth pulp (core) is located. It has two parts: the crown and the root. The pulp is made up of connective tissue that makes the crown soft connective tissue. Rich in a variety of cells, it contains fine collagen and precollagen fibers. The pulp at the root of the tooth is made up of harder, thicker connective tissue, and the collagen fibers are mostly longitudinal around the nerve vessels. Depending on the composition of the cell structure, the pulp is divided into three zones: outer, middle and central. In the outer peripheral zone, there are specific noxious cells that form several layers odontoblasts, which form dentin. It has a single long fiber that goes into the dentinal tubules and is called the Thoms fiber. It plays an important role in the nutrition, innervation and metabolism of enamel and dentin. Toms fibers are wrapped in a thin organic film and end mainly at the enamel dentin boundary. In addition to a single long peripheral fiber, odontoblasts have several short tiny fibers that are inextricably linked. In the middle, periodontoblast, or subodontoblast zone, there are several layers of noxious cells with only a few short fibers. Periodontoblasts form odontoblasts, in which one of the short fibers elongates and settles in the dentinal canals. In the central zone there are small, granular, star-shaped cells, microphages - histrocytes. Hystrocytes have a large nucleus. No elastic fibers were found in the pulp of the tooth, which contains a large number of connective tissue-forming cells and other cells. Inflammation and other pathological conditions can lead to various changes. Fibroblasts contain many tiny fibers that bind to each other and form collagen fibers. When there is inflammation, the fibroblasts form a 
fibrous sac and try to keep the inflammation from spreading. From the holes at the tip of the tooth root and around it, the pulp enters the nerve fibers, arterial blood vessels. The tiny blood vessels in the root of the tooth become capillaries. Nerves, blood, and lymphatic vessels are all connected. Nerve fibers form a nodule of tiny nerve fibers below and above the odontoblasts.

\section{CONCLUSION}

The main function of the dental pulp is to form, nourish, partial enamel is also involved in metabolism. The periodontium is located in the periodontal cavity. The thickness of this gap is normally $0.1-0.2 \mathrm{~mm}$, the inner part is covered with cement, the outer part is covered with a tumor of the jaw bone, the upper part is a physiological dental pocket, and the bottom is a nerve-blood entering the tooth. bounded by the sum of the vessels. Periodont, or perisement, is a Latin word meaning "tooth edge," "circumference," or "cement edge," and is composed primarily of hard connective tissue fibers. These fibers are as strong as iron and are 4-10 microns thick. Called Sharipeev fibers: the neck of the tooth root is horizontal, forming the circular connecting part of the tooth, and the physiological tooth-gum is the basis of the pocket. In the middle of the tooth root, these fibers are curved, the upper part enters the alveolar growth of the jawbone, and the lower part enters the cementum. In three parts of the tooth root, these fibers are in a vertical direction. There is a small amount of soft connective tissue between the Sharipeev fibers that acts as a cushion. The pressure on the tooth spreads throughout the periodontium. This soft tissue contains fibroblasts, fibrocytes, plasma, lymphatic and other cells. It also contains residual epithelial Malyasse cells, which multiply when tumors form. Near the cement, there are cement blasts, cementocytes, and near the alveolar growth of the jaw bone, osteoblasts, osteocytes, which provide plasticity to the periodontium. The periodontium performs a trophic function because the connective tissue fibers in the periodontium are connected to the dentin fibers through the gums, jawbone, and cementum. That is, the osmosis of the teeth, albeit to a lesser extent, nourishes the tooth tissue, mainly cement, dentin, through the fibers. After the pulp is removed and the crowns are filled, these teeth will last for ten years because of the periodontium. The periodontium is connected to nerves, lymph, blood vessels, alveolar growths in the jawbone, and nerves, lymph, and blood vessels that enter the periodontium.

\section{REFERENCES}

1. Jean M. Bruch Nathaniel S. Treister. Clinical dentistry and pathology. Springer International Publishing, 2nd Publish . USA. Feb 2016

2. Borovskiy E.V. I et al. Therapeutic dentistry: Textbook - M, 1989.

3. Abdullahodzhaeva M.S., Akbarova M.T. Atlas of the pathological anatomy of diseases of the dentition and oral sex organs. 1983 year

4. Borovsky E.V., Danilevsky N.F. Atlas of diseases of the oral mucosa. - Moscow "Medicine" 1981.

5. Banchenko G.V., Maksimov YM. Language is a "mirror" organization. M. Business center "Dentistry" 2000. (Department Library)

6. Barer G. Therapeutic dentistry. Part 3. Diseases of the oral mucosa. Moscow. "GEOTAR-Media" 2005 (Electronic)

7. www. medical library.ru 

(ISSN - 2689-1026)

Published: December 12, 2020 | Pages: 1-5

Doi: https://doi.org/10.37547/TAJMSPR/Volume02Issue12-01

8. www.medline.ru

9. www. med.ru. 